FEDERAL RESERVE BANK OF SAN FRANCISCO

WORKING PAPER SERIES

\title{
Is There an On-the-Run Premium in TIPS?
}

Jens H. E. Christensen

Jose A. Lopez

Patrick Shultz

Federal Reserve Bank of San Francisco

September 2017

Working Paper 2017-10

http://www.frbsf.org/economic-research/publications/working-papers/wp2017/10

\section{Suggested citation:}

Christensen, Jens H. E., Jose A. Lopez, Patrick Shultz. 2017. "Is there an On-The-Run Premium in TIPS?” Federal Reserve Bank of San Francisco Working Paper 2017-10.

https://doi.org/10.24148/wp2017-10

The views in this paper are solely the responsibility of the authors and should not be interpreted as reflecting the views of the Federal Reserve Bank of San Francisco or the Board of Governors of the Federal Reserve System. 


\title{
Is There an On-the-Run Premium in TIPS?
}

\author{
Jens H. E. Christensen \\ Jose A. Lopez \\ Patrick Shultz \\ Federal Reserve Bank of San Francisco \\ 101 Market Street \\ San Francisco, CA 94105
}

\begin{abstract}
In the U.S. Treasury market, the most recently issued, or so-called "on-the-run," security typically trades at a price above those of more seasoned but otherwise comparable securities. This difference is known as the on-the-run premium. In this paper, yield spreads between pairs of Treasury Inflation-Protected Securities (TIPS) with identical maturities but of separate vintages are analyzed. Adjusting for differences in coupon rates and values of embedded deflation options, the results show a small, positive premium on recently issued TIPS - averaging between one and four basis points - that persists even after new similar TIPS are issued and hence is different from the on-the-run phenomenon observed in the nominal Treasury market.
\end{abstract}

JEL Classification: E43, E47, G12, G13 Keywords: term structure models, liquidity risk, financial market frictions

The views in this paper are solely the responsibility of the authors and should not be interpreted as reflecting the views of the Federal Reserve Bank of San Francisco or the Federal Reserve System.

This version: September 25, 2017. 


\section{Introduction}

For standard Treasury securities, it is a long-established empirical fact that the most recently issued security of a given maturity tends to trade at a higher price than more seasoned but otherwise comparable Treasury securities; see Goldreich et al. (2005). This difference is referred to as the "on-the-run" premium and reflects their added convenience for ease of trading and for use in repurchase transactions; see Duffie (1996) and Keane (1996) for discussions. In this paper, we examine whether a similar premium exists for recently issued Treasury Inflation-Protected Securities (TIPS), which are specialized Treasury securities that offer investors protection against inflation and some protection against deflation over the life of the bond. In particular, investors are guaranteed the return of the original principal even if prices decline on net over the life of the bond. Hence, they are likely to be attractive to a different set of investors and have different relative price patterns.

For empirical evidence and econometric identification, our analysis exploits the fact that the U.S. Treasury has issued several 20-year TIPS in the past whose maturity dates are exactly identical to those of newly issued 10-year TIPS. This coincidence provides an ideal natural experiment for studying on-the-run premiums in TIPS prices. In particular, focusing on yield differences between such bond pairs eliminates the need to account for differences in credit risk, maturity mismatches, investor risk preferences, and related factors that have plagued other studies in this area. However, merely looking at the yield difference between such pairs of matching TIPS is not sufficient due to the values of their embedded deflation protection options and differences in their coupon rates.

To overcome those challenges, we use a dynamic term structure model introduced in Christensen, Lopez, and Rudebusch (2016, henceforth CLR), which allows us to account accurately for both of these effects in the observed yield spreads. ${ }^{1}$ Specifically, we estimate the model daily in real time and use the generated TIPS yield curves to calculate the value of the embedded deflation options. While such options are without value in seasoned TIPS due to their sizable accrued inflation compensation, they are close to being at the money - and therefore of some value - for the recently issued TIPS in each pair. Furthermore, we refine the estimated deflation option values for the recently issued TIPS by adjusting them for both liquidity effects following an approach similar to CLR and effects tied to changes in their level of accrued inflation compensation. In a final step, we use the model to adjust for the effect of the coupon differential in each TIPS pair.

Combining the option and coupon adjustments, we get an estimate of what the yield spreads in our TIPS pairs should be under an assumption of fair pricing. Deducting that from the observed yield spreads generates an unexplained residual that represents a measure of the premium investors attach to the recently issued 10-year TIPS. The results reveal that

\footnotetext{
${ }^{1}$ In the appendix, we show that our results are robust to using the TIPS yields produced by Gürkaynak et al. (2010) instead of the fitted TIPS yields from the CLR model.
} 
these TIPS carry a small, positive premium - averaging between one and four basis points that persists long after new 10-year TIPS are issued. While our results for the TIPS market share some similarities with the yield differences between seasoned re-opened and newly issued Treasury bills as described in Fleming (2002), they are different from the general patterns observed in the Treasury note market, where on-the-run premiums tend to dissipate around the time the securities go off the run. As a consequence, we conclude that the on-the-run phenomenon appears indeed to be unique to the nominal Treasury bond market, likely due to the extreme liquidity of newly issued Treasury securities.

A few caveats are in order. As shown in Figure 1 below, on-the-run premiums in the Treasury market have been below average during the recent period we study, which may be reflected in our results and make it hard to identify premiums unique to the on-the-run period. However, as data on new TIPS pairs becomes available in coming years, monitoring these premiums will be straightforward and will shed more light on this issue. Another helpful development should be positive inflation in the years ahead, which will reduce the deflation option values for the newly issued TIPS to zero and leave only coupon adjustments to consider. This development will allow for a more direct assessment of the longer-run trend in the yield spreads of our TIPS pairs. Thus, while current evidence suggests that the TIPS market has smaller on-the-run premiums than the nominal Treasury market, new data generated over the next few years should allow us to answer this question more comprehensively.

Finally, we note that the detected patterns in the yield spreads for each TIPS pair could be caused by unobserved differences in how much of each security has been, or is expected to be, held by different types of investors. In a recent paper, Andreasen et al. (2017) introduce a theoretically consistent dynamic term structure model that allows for such differences across individual bonds and accounts for the associated effects on the bonds' liquidity premiums. However, given that they only consider 5- and 10-year TIPS based on a sample ending in 2013, their results cannot speak to the variation in our data, which covers a later period and includes 20-year TIPS. It therefore remains an open question whether that type of model would be consistent with the relative TIPS pricing patterns we observe.

The remainder of the paper is structured as follows. Section 2 describes the well-documented on-the-run premium in the Treasury market, and Section 3 offers a brief description of the market for TIPS. Section 4 details the CLR model of nominal and real yields that we rely on for our assessment, while Section 5 explains how deflation option values are calculated and adjusted for liquidity effects and accrued inflation compensation. Section 6 contains the empirical results, while Section 7 concludes and offers directions for future research. The appendix contains additional analysis of the bond prices in our TIPS pairs. 


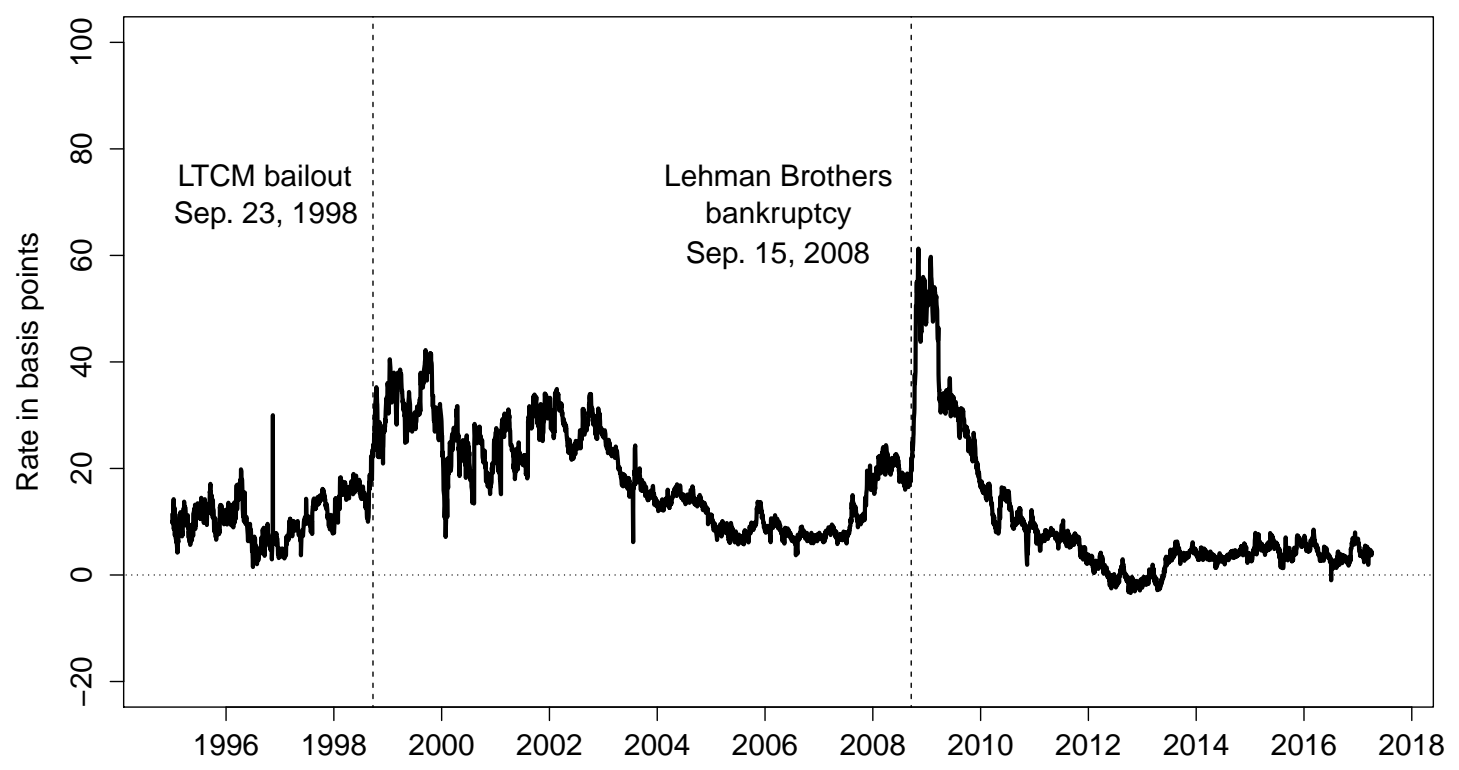

Figure 1: 10-Year Treasury On-The-Run Premium

\section{The On-The-Run Premium in Treasuries}

For standard Treasury securities, it is a long standing observation that the most recently issued security of a given maturity trades at a higher price than more seasoned but otherwise comparable Treasury securities. A measure of the Treasury on-the-run premium is shown in Figure 1 and derived from the difference between par-coupon yields of seasoned 10-year Treasury bonds (as per Gürkaynak et al. (2007)) and the yields on newly issued 10-year Treasury bonds (as reported in the Federal Reserve's H.15 series). This yield spread has been positive since 1995 with the exception of a brief period between May 2012 and May 2013. It has averaged about 14 basis points (or $0.14 \%$ ) and varies notably with persistent shocks that cause it to deviate from its mean for extended periods. In particular, the collapse of Long-Term Capital Management (LTCM) during the Russian sovereign debt crisis in the fall of 1998 and the bankruptcy of Lehman Brothers in September 2008 during the financial crisis caused sharp persistent spikes in this premium, which suggests that part of its variation reflect systematic economy-wide risks.

An early reference for research on the price differentials between seasoned and recently issued Treasury securities is Amihud and Mendelson (1991), who study yield differences between maturity-matched Treasury bills and notes with less than six months to expiry. They demonstrate that seasoned notes tend to trade at a higher yield to maturity than comparable Treasury bills. They also note that there are similar differences in their current market 
liquidity as measured by both bid-ask spreads and brokerage fees. The logic of their analysis would seem to extend in a straightforward way to the TIPS market given that bid-ask spreads of seasoned TIPS tend to be above those of more recently issued TIPS as we document in the next section. However, at the same time they find that the yield differences are a linear function of the reciprocal of the time to maturity, i.e., a decreasing convex function of the time to expiry, which could suggest that the yield differences may be negligible for the TIPS we examine with longer times to maturity.

Krishnamurthy (2002) analyzes the returns on a simple trading strategy that short-sells new on-the-run 30-year Treasury bonds and uses the proceeds to buy the "old" 30-year Treasury bond that just went off the run. For the period from June 10, 1995, to November 15, 1999, he reports that the yield differences between such pairs of Treasury bonds averaged 6.25 basis points, although the average profit from this strategy is close to zero once the costs in the repo market of shorting the on-the-run Treasury bond are taken into account. Furthermore, he shows that the profits on such convergence trades exhibit notable time variation and turned significantly negative in the fall of 1998 , which was one of the factors behind the collapse of LTCM and its convergence trades. Finally, he establishes a negative relationship between the auction size and the on-the-run premium, which underscores that part of it reflects a scarcity of liquid long-term assets.

A more detailed characterization of Treasury on-the-run premiums is provided in Goldreich et al. (2005), who document the existence of significant on-the-run premiums in 2-year Treasury notes, averaging 1.5 basis points during the period from January 1994 to December 2000. Furthermore, they find a systematic pattern in their bid-ask spreads that start out low and gradually increase over time with a notable uptick around the time the securities go off the run. Similarly, trade size declines by more than 50 percent, and daily trading volume drops from over $\$ 6$ billion per day to around $\$ 100$ million during the short transition window. These empirical findings are evidence of a dramatic decline in market liquidity when these securities go off the run. Importantly, they also find no detectable premium in the yields once off-the-run, such that these are properties tied uniquely to the on-the-run period. Finally, they offer evidence that on-the-run premiums are primarily determined by measures of expected future liquidity and not by the securities' current liquidity.

Echoing this evidence, Barclay et al. (2006) describe the decline in trading volume as Treasury securities go off the run. The drop is instantaneous and dramatic at more than 90 percent overnight, and it holds for all Treasury notes independent of maturity. In addition, the average time between trades in their data is roughly 100 times longer for off-the-run Treasuries. Practically speaking, they document that Treasury trades go from being rapidly executed via electronic platforms while on the run to slower execution primarily through voice brokers once off the run.

Fleming (2002) offers a different perspective. Using data from July 1, 1996, to December 
31, 2000, he shows that new 26-week Treasury bills trade at a lower yield than comparable, but more seasoned 52-week Treasury bills despite the fact that the latter have lower bid-ask spreads, higher trading volumes, and larger outstanding notional. 52-week Treasury bills that are re-opened and therefore larger than comparable 26-week Treasury bills have yields that average 2.4 basis points above those of otherwise comparable bills. Furthermore, this difference increases to 3.2 basis points when the securities have 13 weeks to maturity and both have been re-opened. Thus, Fleming (2002) documents price differences that are much more persistent than the on-the-run phenomenon described in Goldreich et al. (2005) and he argues that any indirect liquidity benefits are more than offset by the direct supply costs in line with the findings of Krishnamurthy (2002).

In terms of determinants of on-the-run premiums, Keane (1996) shows that repo specialness is one factor affecting on-the-run premiums in the Treasury market as originally suggested by Duffie (1996). Graveline and McBrady (2011) use data for overnight repo special rates for on-the-run 5-year and 10-year Treasury notes covering the period from July 1996 to June 2001 and highlight two sources underlying the Treasury on-the-run premium. First, institutional investors value their high liquidity and are reluctant to lend them out to the repo market, which confirms the results of Keane (1996). Second, premiums in the repo market are partly determined by investors' desire to hedge the interest rate risk of their fixed-income portfolios and may therefore represent an independent, demand-side factor driving Treasury on-the-run premiums.

Finally, Fontaine and Garcia (2012) study maturity-matched pairs of recently issued and seasoned Treasury notes and document systematic age effects, i.e., low age or recently issued bonds are overpriced relative to old age bonds. Since recently issued bonds in their construction mostly are on-the-run securities, it is not clear whether their results should be interpreted as a measure of on-the-run premiums or merely reflect price differentials due to aging effects, regardless of being on or off the run. ${ }^{2}$ For our purposes, the key empirical question left behind by this research is whether the structural reasons used to explain on-the-run premiums in the Treasury market are likely to also apply to the market for TIPS and produce on-the-run premiums in their prices. The rest of the paper is dedicated to analyzing this question.

\section{The Market for TIPS}

The U.S. Treasury started issuing TIPS in 1997. The first TIPS was issued on February 6, 1997, with maturity on January 15, 2007, and a coupon rate of $3.375 \%{ }^{3}$ Since then the U.S. Treasury has issued 5-, 10-, 20-, and 30-year TIPS. However, only 10-year TIPS have been issued regularly since the inception of the TIPS program. As of March 31, 2017, a total of 64

\footnotetext{
${ }^{2}$ Early studies by Sarig and Warga (1989) as well as Warga (1992) suffer from similar ambiguity.

${ }^{3}$ TIPS are issued with a minimum coupon of $0.125 \%$. Since April 2011, this has been a binding constraint for 5-year TIPS and occasionally for 10-year TIPS.
} 


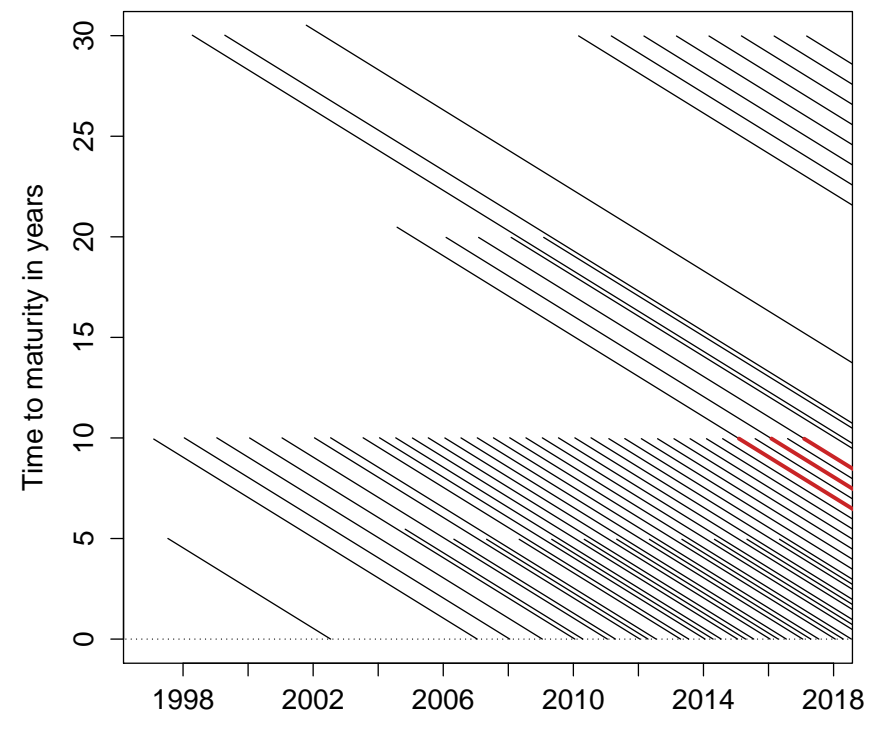

Figure 2: Maturity Distribution of TIPS

Illustration of the maturity distribution of all TIPS issued since the inception of the TIPS program shown with solid black lines. Thick red lines highlight matching pairs of TIPS as described in the main text.

TIPS had been issued with 41 still outstanding. The distribution of their remaining times to maturity across time is shown in Figure 2. In the figure, the three matching pairs of seasoned 20-year TIPS and recently issued 10-year TIPS that we examine are highlighted with thick red lines.

Since January 2004, the Treasury has been issuing new 10-year TIPS bonds regularly twice a year in January and July with maturities ten years later on January 15 and July 15, respectively. Importantly for our analysis, between October 2004 and January 2009, the Treasury also issued five 20-year TIPS, each with maturity twenty years later on January 15. As a result, there are currently three pairs of TIPS trading with identical maturities: the first pair matures on January 15, 2025 (with identifying CUSIP numbers of 912810FR4 and 912828H45), the second pair matures on January 15, 2026 (CUSIP numbers 912810FS2 and 912828N71), while the third pair matures on January 15, 2027 (CUSIP numbers 912810PS and 912828V49). We identify them as the 2025 TIPS pair, the 2026 TIPS pair, and the 2027 TIPS pair, respectively. Eventually, by January 2019, there will be five such pairs of matching TIPS trading simultaneously assuming a continuation of the Treasury's current issuance pattern. Furthermore, please note that since the Treasury only tends to re-open securities within one year of their original issuance, it likely did not consider re-opening the seasoned 20-year bonds as an alternative to issuing the new 10-year bonds. Table 1 contains 


\begin{tabular}{|l|c|c|c|c|c|c|}
\hline \multirow{2}{*}{2025 TIPS pair } & \multicolumn{2}{|c|}{ Issuance } & \multicolumn{2}{c|}{ First reopen } & \multicolumn{2}{c|}{ Second reopen } \\
\cline { 2 - 7 } & Date & Amount & Date & Amount & Date & Amount \\
\hline $2.375 \% 1 / 15 / 2025$ TIPS & $7 / 30 / 04$ & 11,000 & $1 / 31 / 05$ & 11,000 & $7 / 29 / 05$ & 6,000 \\
$0.25 \% 1 / 15 / 2025$ TIPS & $1 / 30 / 15$ & 15,000 & $3 / 31 / 15$ & 13,000 & $5 / 29 / 15$ & 13,000 \\
\hline
\end{tabular}

\begin{tabular}{|l|c|c|c|c|c|c|}
\hline \multirow{2}{*}{2026 TIPS pair } & \multicolumn{2}{|c|}{ Issuance } & \multicolumn{2}{c|}{ First reopen } & \multicolumn{2}{c|}{ Second reopen } \\
\cline { 2 - 7 } & Date & Amount & Date & Amount & Date & Amount \\
\hline $2 \% 1 / 15 / 2026$ TIPS & $1 / 31 / 06$ & 10,000 & $7 / 31 / 06$ & 7,000 & n.a. & n.a. \\
$0.625 \% 1 / 15 / 2026$ TIPS & $1 / 29 / 16$ & 15,000 & $3 / 31 / 16$ & 11,000 & $5 / 31 / 16$ & 11,000 \\
\hline
\end{tabular}

\begin{tabular}{|c|c|c|c|c|c|c|}
\hline \multirow{2}{*}{2027 TIPS pair } & \multicolumn{2}{|c|}{ Issuance } & \multicolumn{2}{|c|}{ First reopen } & \multicolumn{2}{|c|}{ Second reopen } \\
\hline & Date & Amount & Date & Amount & Date & Amount \\
\hline $2.375 \% 1 / 15 / 2027$ TIPS & $1 / 31 / 07$ & 8,000 & $7 / 31 / 07$ & 6,000 & n.a. & n.a. \\
\hline $0.375 \% 1 / 15 / 2027$ TIPS & $1 / 31 / 17$ & 13,000 & $3 / 31 / 17$ & 11,000 & $5 / 31 / 17$ & 11,000 \\
\hline
\end{tabular}

\section{Table 1: Sample of Matching TIPS Pairs}

The table reports the characteristics, issuance dates, and issuance amounts in millions of dollars for the three pairs of TIPS used in the analysis.

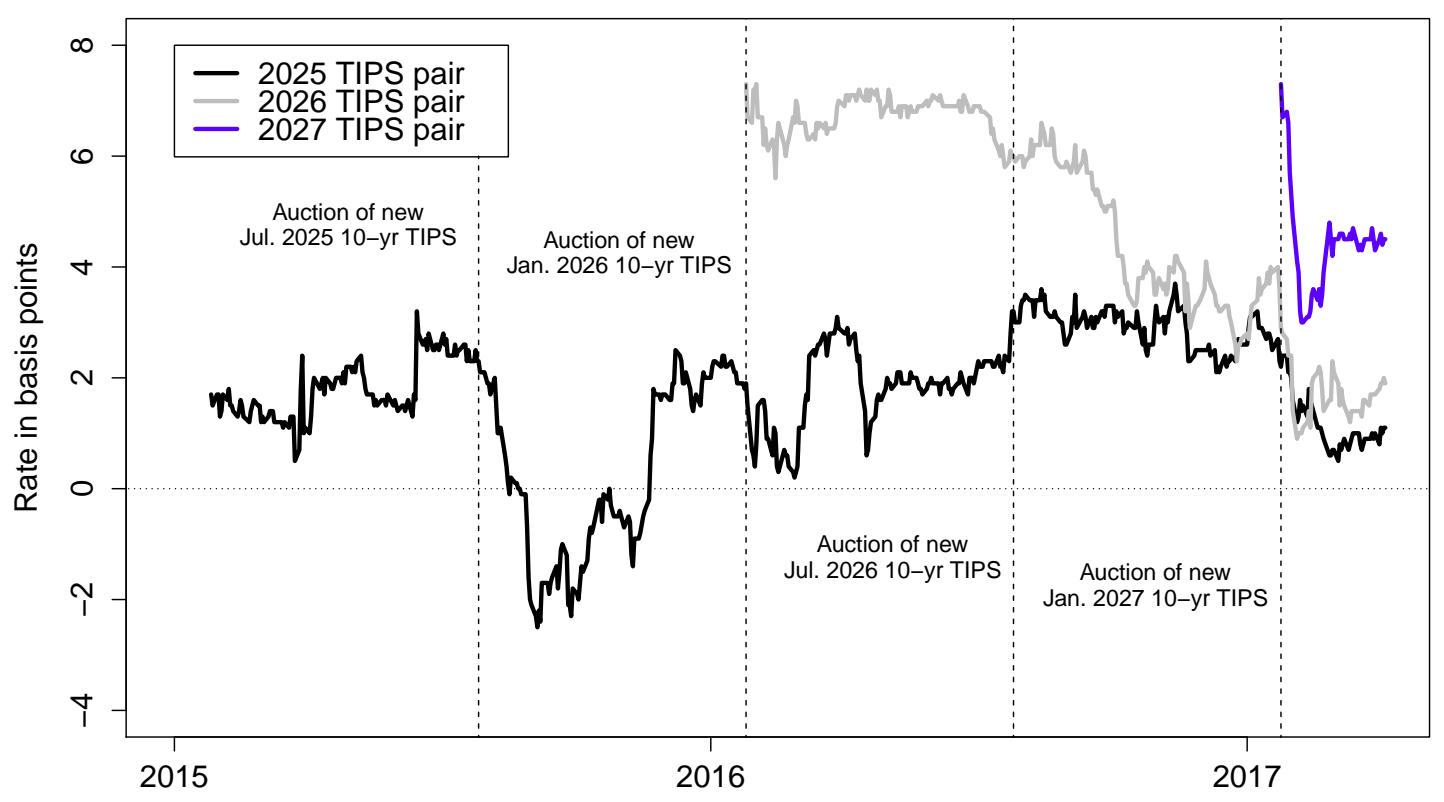

Figure 3: Yield Spreads of TIPS Pairs

the contractual details of each TIPS bond in our pairs.

Crucially, only two characteristics distinguish the two bonds in each TIPS pair: their coupon rates and their accrued inflation compensation, which reflects their net inflation experience since issuance. Note that the latter directly affects the value of the embedded deflation 


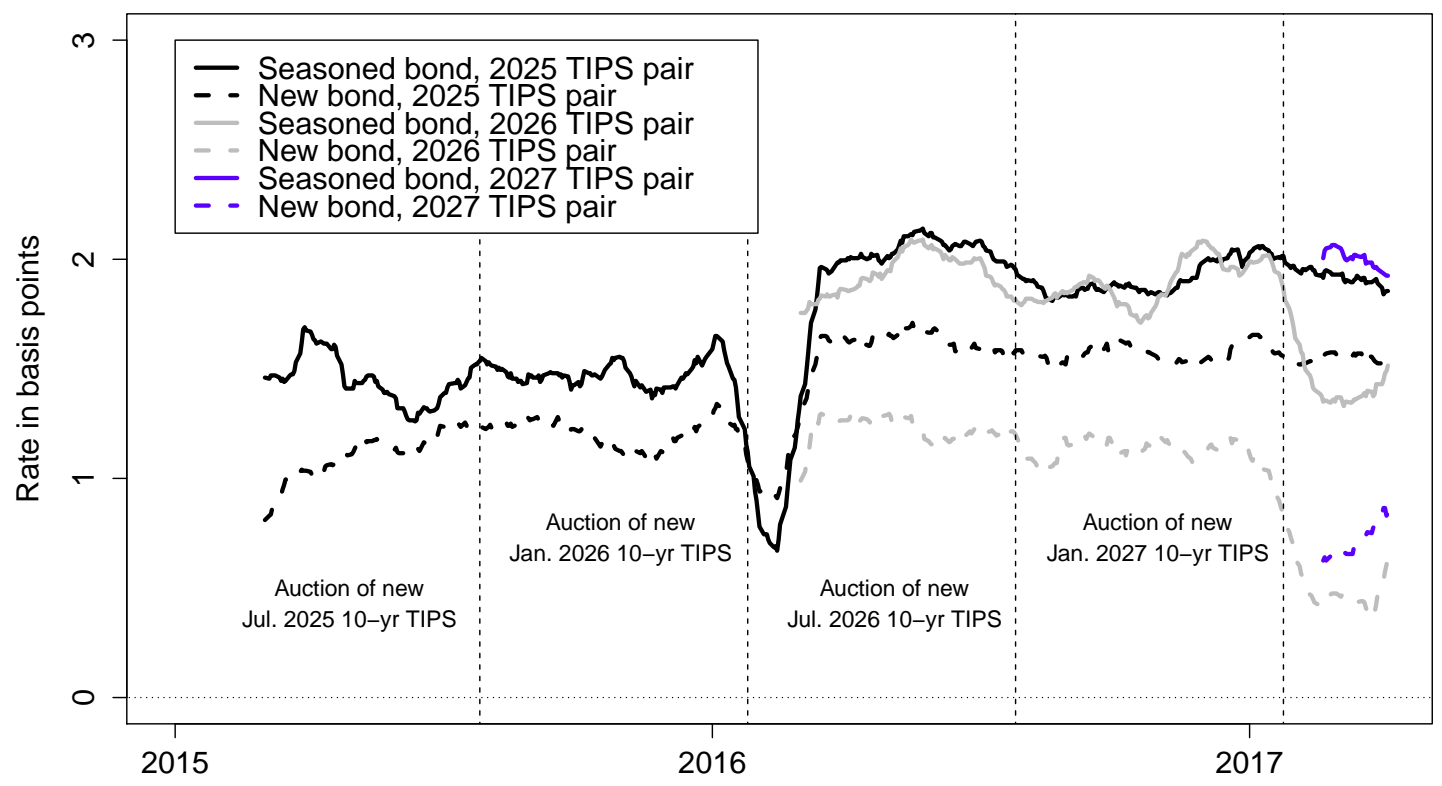

Figure 4: Bid-Ask Spreads of TIPS Pairs

protection provided by these securities. As all other aspects are exactly identical except some differences in the outstanding notional, these pairs provide an ideal natural experiment with which to study whether there is an on-the-run premium in the pricing of TIPS.

Figure 3 shows the differences in the mid-market yields to maturity. First, the yield difference for each TIPS pair is positive on average with means of 1.7 basis points, 5.0 basis points, and 4.4 basis points for the 2025 pair, 2026 pair, and 2027 pair, respectively. Second, the yield differences persist long after new 10-year TIPS have been issued, which offers the first indication that premiums on recently issued TIPS may have different dynamic profiles than the well-known on-the-run premiums in the Treasury market. Recall that these premia were reported to dissipate around the time the securities went off the run by Goldreich et al. (2005). Finally, they exhibit notable time variation with some tendency to drift lower over time. Combined this could suggest that there is a premium on recently issued TIPS, but as already explained we need to adjust for both coupon differentials and the embedded value of the deflation protection in the recently issued 10-year TIPS.

In principle, arguments can be made for and against the existence of an on-the-run premium for TIPS. The reasons for its existence in the Treasury market as laid out in the previous section could also apply to the TIPS market; specifically, recently issued TIPS could be more desirable for trading transactions and therefore more liquid. This view is supported by data on the bid-ask spreads for the TIPS in our pairs, which are sourced from Bloomberg and 


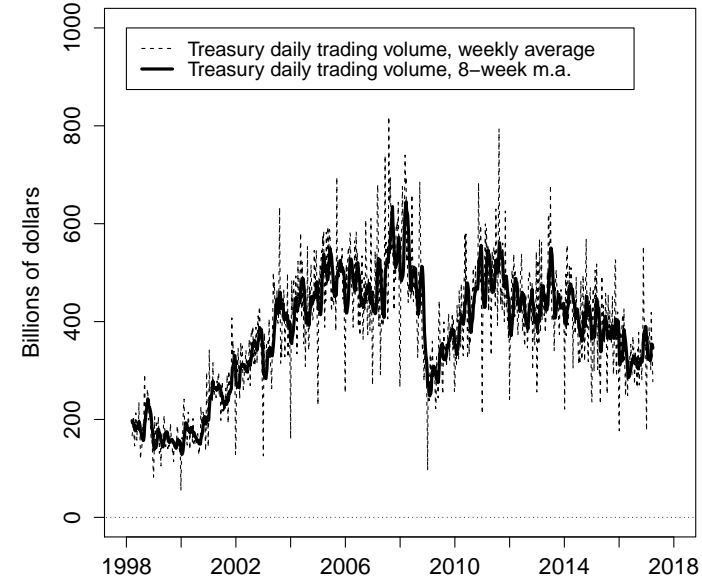

(a) Treasury trading volumes

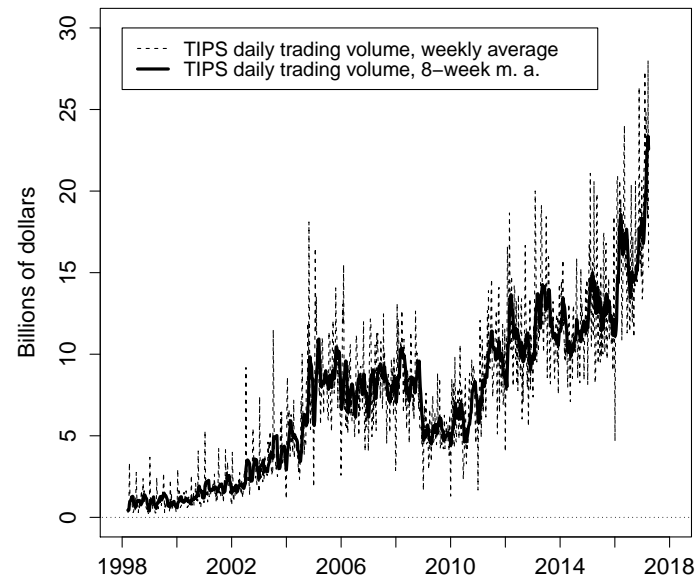

(b) TIPS trading volumes

Figure 5: Treasury and TIPS Trading Volumes

Panel (a) shows the weekly average of daily trading volumes in the secondary market for Treasury coupon bonds (dashed black line) and the smoothed eight-week moving average (solid black line). Panel (b) shows the weekly average of daily trading volumes in the secondary market for TIPS (dashed black line) and the smoothed eight-week moving average (solid black line).

illustrated in Figure 4. Note that the bid-ask spreads of the seasoned security in each TIPS pair are systematically $30 \%$ to $100 \%$ higher. Economically, though, the differences appear to be negligible as their magnitude is less than one basis point.

The matched TIPS pairs are centered around newly issued 10-year TIPS, which are the most liquid TIPS securities as per Fleming and Krishnan (2012). On the other hand, TIPS are much less liquid than regular Treasuries. Evidence in support of this view is provided in Figure 5, which shows the average daily trading volumes in Treasuries and TIPS measured weekly since 1998 (actual and 8-week m.a.). ${ }^{4}$ Note that the outstanding notional of TIPS in the hands of the public represented $\$ 1.25$ trillion as of March 31, 2017, or $9.0 \%$ of all marketable Treasury debt. ${ }^{5}$ However, the trading volumes of Treasuries are roughly 20 times larger than those of TIPS. This implies that each dollar of notional is traded twice as much in the Treasury market as compared to the TIPS market, which might suggest a lower or insignificant on-the-run premium for TIPS. Ultimately, its size is an empirical question, but before we can turn to the empirical analysis, we need to introduce the CLR model of Treasury and TIPS yields that we rely on for our assessment.

\footnotetext{
${ }^{4}$ The trading volume data are available at: http://www.newyorkfed.org/markets/statrel.html.

${ }^{5}$ See the link: https://www.treasurydirect.gov/govt/reports/pd/mspd/2017/opds032017.pdf
} 


\section{The CLR Model}

The joint four-factor model of nominal and real yields we use to account for differences in deflation option values and coupon rates in our TIPS pairs was developed in CLR. Even though the model is not formulated using the canonical form of affine term structure models introduced by Dai and Singleton (2000), it can be viewed as a restricted version of the corresponding canonical model. The restrictions imposed are motivated by a desire to generate a factor loading structure in the zero-coupon bond yield functions that closely matches the popular Nelson and Siegel (1987) model and obtain a model that is well identified and straightforward to estimate. The model's state vector is denoted by $X_{t}=\left(L_{t}^{N}, S_{t}, C_{t}, L_{t}^{R}\right)$, where $L_{t}^{N}$ is a level factor for nominal yields, $S_{t}$ is a common slope factor, $C_{t}$ is a common curvature factor, and $L_{t}^{R}$ is a level factor for real yields. The instantaneous nominal and real risk-free rates are defined as:

$$
\begin{aligned}
& r_{t}^{N}=L_{t}^{N}+S_{t}, \\
& r_{t}^{R}=L_{t}^{R}+\alpha^{R} S_{t} .
\end{aligned}
$$

To preserve a Nelson-Siegel (1987) factor loading structure, the $Q$-dynamics of the state variables are given by

$$
\begin{aligned}
\left(\begin{array}{c}
d L_{t}^{N} \\
d S_{t} \\
d C_{t} \\
d L_{t}^{R}
\end{array}\right) & =\left(\begin{array}{cccc}
\kappa_{L^{N}}^{Q} & 0 & 0 & 0 \\
0 & \lambda & -\lambda & 0 \\
0 & 0 & \lambda & 0 \\
0 & 0 & 0 & \kappa_{L^{R}}^{Q}
\end{array}\right)\left[\left(\begin{array}{c}
\theta_{L^{N}}^{Q} \\
0 \\
0 \\
\theta_{L^{R}}^{Q}
\end{array}\right)-\left(\begin{array}{c}
L_{t}^{N} \\
S_{t} \\
C_{t} \\
L_{t}^{R}
\end{array}\right)\right] d t \\
& +\left(\begin{array}{cccc}
\sigma_{11} & 0 & 0 & 0 \\
0 & \sigma_{22} & 0 & 0 \\
0 & 0 & \sigma_{33} & 0 \\
0 & 0 & 0 & \sigma_{44}
\end{array}\right)\left(\begin{array}{cccc}
\sqrt{L_{t}^{N}} & 0 & 0 & 0 \\
0 & \sqrt{1} & 0 & 0 \\
0 & 0 & \sqrt{1} & 0 \\
0 & 0 & 0 & \sqrt{L_{t}^{R}}
\end{array}\right)\left(\begin{array}{c}
d W_{t}^{L^{N}, Q} \\
d W_{t}^{S, Q} \\
d W_{t}^{C, Q} \\
d W_{t}^{L^{R}, Q}
\end{array}\right) .
\end{aligned}
$$

The representation of the nominal zero-coupon bond yield function becomes

$$
y_{t}^{N}(\tau)=g^{N}\left(\kappa_{L^{N}}^{Q}\right) L_{t}^{N}+\left(\frac{1-e^{-\lambda \tau}}{\lambda \tau}\right) S_{t}+\left(\frac{1-e^{-\lambda \tau}}{\lambda \tau}-e^{-\lambda \tau}\right) C_{t}-\frac{A^{N}\left(\tau ; \kappa_{L^{N}}^{Q}\right)}{\tau},
$$

where $g^{N}\left(\kappa_{L^{N}}^{Q}\right)$ is the loading on the nominal level factor. This structure implies that the slope and curvature factors preserve their Nelson-Siegel (1987) factor loadings exactly. Correspondingly, the real zero-coupon bond yield function is

$$
y_{t}^{R}(\tau)=g^{R}\left(\kappa_{L^{R}}^{Q}\right) L_{t}^{R}+\alpha^{R}\left(\frac{1-e^{-\lambda \tau}}{\lambda \tau}\right) S_{t}+\alpha^{R}\left(\frac{1-e^{-\lambda \tau}}{\lambda \tau}-e^{-\lambda \tau}\right) C_{t}-\frac{A^{R}\left(\tau ; \kappa_{L^{R}}^{Q}\right)}{\tau},
$$


where $g^{R}\left(\kappa_{L^{R}}^{Q}\right)$ is the loading on the real level factor. ${ }^{6}$ Note that $A^{N}\left(\tau ; \kappa_{L^{N}}^{Q}\right) / \tau$ and $A^{R}\left(\tau ; \kappa_{L^{R}}^{Q}\right) / \tau$ are so-called yield-adjustment terms that ensure absence of arbitrage. ${ }^{7}$

To link the risk-neutral and real-world dynamics of the state variables, we follow CLR and use the extended affine risk premium specification introduced by Cheridito et al. (2007). The maximally flexible affine specification of the $P$-dynamics is thus

$$
\begin{aligned}
\left(\begin{array}{c}
d L_{t}^{N} \\
d S_{t} \\
d C_{t} \\
d L_{t}^{R}
\end{array}\right) & =\left(\begin{array}{cccc}
\kappa_{11}^{P} & 0 & 0 & \kappa_{14}^{P} \\
\kappa_{21}^{P} & \kappa_{22}^{P} & \kappa_{23}^{P} & \kappa_{24}^{P} \\
\kappa_{31}^{P} & \kappa_{32}^{P} & \kappa_{33}^{P} & \kappa_{34}^{P} \\
\kappa_{41}^{P} & 0 & 0 & \kappa_{44}^{P}
\end{array}\right)\left[\left(\begin{array}{c}
\theta_{1}^{P} \\
\theta_{2}^{P} \\
\theta_{3}^{P} \\
\theta_{4}^{P}
\end{array}\right)-\left(\begin{array}{c}
L_{t}^{N} \\
S_{t} \\
C_{t} \\
L_{t}^{R}
\end{array}\right)\right] d t \\
& +\left(\begin{array}{cccc}
\sigma_{11} & 0 & 0 & 0 \\
0 & \sigma_{22} & 0 & 0 \\
0 & 0 & \sigma_{33} & 0 \\
0 & 0 & 0 & \sigma_{44}
\end{array}\right)\left(\begin{array}{cccc}
\sqrt{L_{t}^{N}} & 0 & 0 & 0 \\
0 & \sqrt{1} & 0 & 0 \\
0 & 0 & \sqrt{1} & 0 \\
0 & 0 & 0 & \sqrt{L_{t}^{R}}
\end{array}\right)\left(\begin{array}{c}
d W_{t}^{L^{N}, P} \\
d W_{t}^{S, P} \\
d W_{t}^{C, P} \\
d W_{t}^{L^{R}, P}
\end{array}\right) .
\end{aligned}
$$

To keep the model arbitrage-free, the two level factors must be prevented from hitting the lower zero-boundary. This positivity requirement is ensured by imposing the Feller conditions under both probability measures, which in this case are four; that is,

$$
\kappa_{11}^{P} \theta_{1}^{P}+\kappa_{14}^{P} \theta_{4}^{P}>\frac{1}{2} \sigma_{11}^{2}, \quad 10^{-7} \cdot \theta_{L^{N}}^{Q}>\frac{1}{2} \sigma_{11}^{2}, \quad \kappa_{41}^{P} \theta_{1}^{P}+\kappa_{44}^{P} \theta_{4}^{P}>\frac{1}{2} \sigma_{44}^{2}, \quad 10^{-7} \cdot \theta_{L^{R}}^{Q}>\frac{1}{2} \sigma_{44}^{2} .
$$

Furthermore, to have well-defined processes for $L_{t}^{N}$ and $L_{t}^{R}$, the sign of the effect that these two factors have on each other must be positive, which requires the restrictions that

$$
\kappa_{14}^{P} \leq 0 \quad \text { and } \quad \kappa_{41}^{P} \leq 0 .
$$

These conditions ensure that the two square-root processes will be nonnegatively correlated.

Since the value of the TIPS deflation option is insensitive to the specification of the meanreversion matrix $K^{P}$, we use the most parsimonious specification of the objective $P$-dynamics where this matrix is diagonal

$$
\left(\begin{array}{c}
d L_{t}^{N} \\
d S_{t} \\
d C_{t} \\
d L_{t}^{R}
\end{array}\right)=\left(\begin{array}{cccc}
\kappa_{11}^{P} & 0 & 0 & 0 \\
0 & \kappa_{22}^{P} & 0 & 0 \\
0 & 0 & \kappa_{33}^{P} & 0 \\
0 & 0 & 0 & \kappa_{44}^{P}
\end{array}\right)\left[\left(\begin{array}{c}
\theta_{1}^{P} \\
\theta_{2}^{P} \\
\theta_{3}^{P} \\
\theta_{4}^{P}
\end{array}\right)-\left(\begin{array}{c}
L_{t}^{N} \\
S_{t} \\
C_{t} \\
L_{t}^{R}
\end{array}\right)\right] d t
$$

\footnotetext{
${ }^{6}$ In our implementation, we fix $\kappa_{L^{N}}^{Q}=\kappa_{L^{R}}^{Q}=10^{-7}$ to get a close approximation to the uniform level factor loading in the Nelson-Siegel (1987) model.

${ }^{7}$ Analytical formulas for $g^{N}\left(\kappa_{L^{N}}^{Q}\right), g^{R}\left(\kappa_{L^{R}}^{Q}\right), A^{N}\left(\tau ; \kappa_{L^{N}}^{Q}\right)$, and $A^{R}\left(\tau ; \kappa_{L^{R}}^{Q}\right)$ are provided in CLR.
} 


$$
+\left(\begin{array}{cccc}
\sigma_{11} & 0 & 0 & 0 \\
0 & \sigma_{22} & 0 & 0 \\
0 & 0 & \sigma_{33} & 0 \\
0 & 0 & 0 & \sigma_{44}
\end{array}\right)\left(\begin{array}{cccc}
\sqrt{L_{t}^{N}} & 0 & 0 & 0 \\
0 & \sqrt{1} & 0 & 0 \\
0 & 0 & \sqrt{1} & 0 \\
0 & 0 & 0 & \sqrt{L_{t}^{R}}
\end{array}\right)\left(\begin{array}{c}
d W_{t}^{L^{N}, P} \\
d W_{t}^{S, P} \\
d W_{t}^{C, P} \\
d W_{t}^{L^{R}, P}
\end{array}\right) .
$$

In the empirical implementation, we use yields at daily frequency. While the sample of nominal yields from Gürkaynak et al. (2007) continues to start in January 1995 as in CLR, we begin the sample of real yields in January 1999 when they become available in the Gürkaynak et al. (2010) database. CLR avoid this earlier data and start their real yield sample in January 2003 out of concerns for elevated TIPS liquidity premiums in the early years. However, for our purposes, it becomes a strength to include the early data as it provides us with a longer sample to use in our regression analysis to control explicitly for such liquidity effects as explained the next section.

\section{TIPS Deflation Options}

In this section, we first describe how TIPS deflation option values can be calculated within the CLR model. Second, we detail how we adjust those values for liquidity effects using regression analysis before we proceed to a description of how we make a final adjustment to account for the effect on the option values of changes in the accrued inflation compensation.

\subsection{Calculation of Deflation Option Values}

To calculate deflation option values, we follow CLR and compare the price of a newly issued TIPS without any accrued inflation compensation to that of a seasoned TIPS with sufficient accrued inflation compensation that the option is worth nothing. First, consider a hypothetical seasoned TIPS with $T$ years remaining to maturity that pays an annual coupon $C$ semi-annually. Assume this bond has accrued sufficient inflation compensation so it is nearly impossible to reach the deflation floor before maturity. Under the risk-neutral pricing measure, the par-coupon bond satisfying these criteria has a coupon rate determined by the equation

$$
\sum_{i=1}^{2 T} \frac{C}{2} E_{t}^{Q}\left[e^{-\int_{t}^{t_{i}} r_{s}^{R} d s}\right]+E_{t}^{Q}\left[e^{-\int_{t}^{T} r_{s}^{R} d s}\right]=1 .
$$

The first term is the sum of the present value of the $2 T$ coupon payments using the model's fitted real yield curve at day $t$. The second term is the discounted value of the principal payment. The coupon payment of the seasoned bond that solves this equation is denoted as $C_{S}$.

Next, consider a new TIPS with no accrued inflation compensation with $T$ years to maturity. Since the coupon payments are not protected against deflation, the difference is in accounting for the deflation protection on the principal payment. For this bond, the pricing 
equation has an additional term; that is,

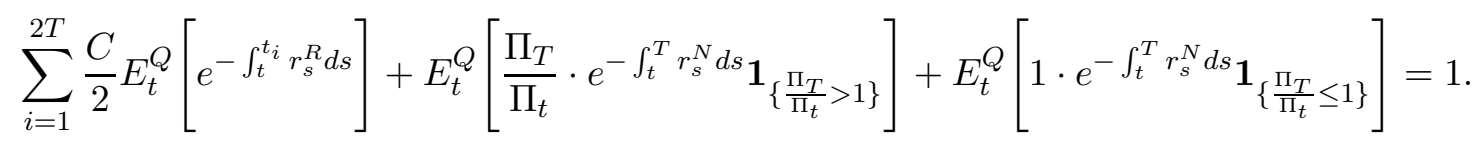

The first term is the same as before. The second term represents the present value of the principal payment conditional on a positive net change in the price index over the bond's maturity; that is, $\frac{\Pi_{T}}{\Pi_{t}}>1$. Under this condition, full inflation indexation applies, and the price change $\frac{\Pi_{T}}{\Pi_{t}}$ is placed within the expectations operator. The third term represents the present value of the floored TIPS principal conditional on accumulated net deflation; that is, when the price level change is below one, $\frac{\Pi_{T}}{\Pi_{t}}$ is replaced by a value of one to provide the promised deflation protection.

Assuming absence of arbitrage it can be shown that the dynamics of the model-implied price index take the form

$$
\frac{\Pi_{T}}{\Pi_{t}}=e^{\int_{t}^{T}\left(r_{s}^{N}-r_{s}^{R}\right) d s}
$$

It then follows that the equation above can be rewritten as

$$
\sum_{i=1}^{2 T} \frac{C}{2} E_{t}^{Q}\left[e^{-\int_{t}^{t_{i}} r_{s}^{R} d s}\right]+E_{t}^{Q}\left[e^{-\int_{t}^{T} r_{s}^{R} d s}\right]+\left[E_{t}^{Q}\left[e^{-\int_{t}^{T} r_{s}^{N} d s} \mathbf{1}_{\left\{\frac{\Pi_{T}}{\Pi_{t}} \leq 1\right\}}\right]-E_{t}^{Q}\left[e^{-\int_{t}^{T} r_{s}^{R} d s} \mathbf{1}_{\left\{\frac{\Pi_{T}}{\Pi_{t}} \leq 1\right\}}\right]\right]=1,
$$

where the last term on the left-hand side represents the net present value of the deflation protection of the principal in the TIPS contract. The par-coupon yield of a new hypothetical TIPS that solves this equation is denoted as $C_{0}$. The difference between $C_{S}$ and $C_{0}$ is a measure of the advantage of being at the inflation adjustment floor for a newly issued TIPS and thus of the value of the embedded deflation protection option.

In the empirical implementation, we perform rolling real-time model estimations on expanding yield samples starting in January 4, 2005, until March 31, 2017. Using the formulas above as described in CLR, this provides us with the real-time estimates of the TIPS deflation option values at the 10-year maturity shown in Figure 6, which is used as the dependent variable in the regression-based liquidity-adjustment detailed in the following.

\subsection{Liquidity-Adjusted Deflation Option Values}

In principle, we should be able to use the estimated deflation option values measured as paryield spreads and shown in Figure 6 directly in our analysis of the on-the-run premium in TIPS. However, it is widely accepted that TIPS yields contain a positive liquidity premium relative to regular Treasury yields; see Christensen et al. (2010) and Fleckenstein et al. (2014) among many others for a discussion. If so, the TIPS yields we observe are higher than what they would be in a world without frictions. In turn, this makes the difference between nominal and real yields (also known as the breakeven inflation rate) artificially low, which 


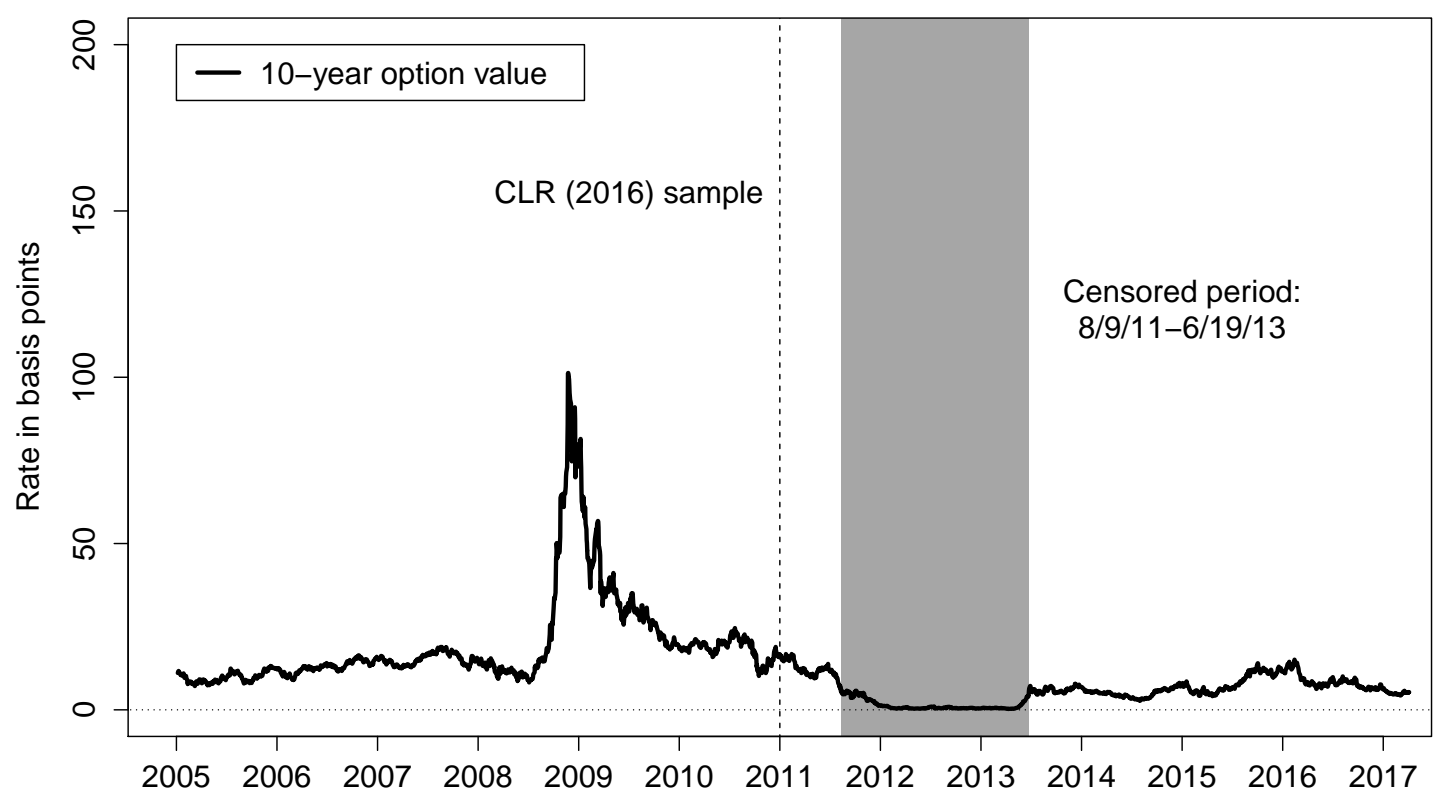

Figure 6: Estimated TIPS Deflation Protection Option Values

Illustration of the spread in the par-coupon yield of a seasoned TIPS over a matching newly issued TIPS implied by the joint model of nominal and real yields introduced in CLR estimated daily in real time over the period from January 4, 2005, to March 31, 2017.

causes the model to produce deflation option values that are too high. Thus, we want to control for such liquidity effects in our analysis. To do so, we follow CLR and use standard linear regressions to distinguish between variation in the actual deflation option value and polluting noise arising from variation in liquidity effects.

In our regressions, the 10-year deflation option series will serve as the dependent variable since it is closest to the maturity of our TIPS pairs, but due to the very high correlation of the deflation option values across maturities, the results are robust to using other maturities. However, the results are sensitive to including the subsample from August 9, 2011, to June 19, 2013, when the interest rate environment was unusually low with short- to medium-term yields compressed against the zero lower bound. ${ }^{8}$ Since the CLR model does not account explicitly for this asymmetry in yield behavior, we choose to censor the data for this period in the regressions.

We use four explanatory variables. The first is the VIX, which represents near-term uncertainty about the general stock market as reflected in one-month options on the Standard \& Poor's 500 stock price index. Thus, the VIX is a measure of priced economic uncertainty that should correlate with the fundamental value of deflation options. The remaining three

\footnotetext{
${ }^{8}$ See Swanson and Williams (2014) for evidence and a discussion.
} 


\begin{tabular}{|c|c|c|c|c|c|}
\hline \multirow{2}{*}{ Explanatory variables } & \multicolumn{5}{|c|}{ 10-year TIPS deflation option value } \\
\hline & $(1)$ & $(2)$ & $(3)$ & $(4)$ & $(5)$ \\
\hline 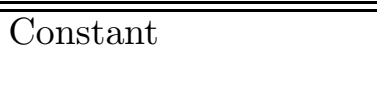 & $\begin{array}{l}-6.63^{* *} \\
(-22.92)\end{array}$ & $\begin{array}{l}4.18^{* *} \\
(17.87)\end{array}$ & $\begin{array}{l}3.01^{* *} \\
(18.39)\end{array}$ & $\begin{array}{l}-2.47^{* *} \\
(-6.62)\end{array}$ & $\begin{array}{l}-3.63^{* *} \\
(-13.82)\end{array}$ \\
\hline VIX & $\begin{array}{l}1.10^{* *} \\
(81.36)\end{array}$ & & & & $\begin{array}{c}0.29^{* *} \\
(15.99)\end{array}$ \\
\hline GSW & & $\begin{array}{l}2.05^{* *} \\
(59.65)\end{array}$ & & & $\begin{array}{c}0.50^{* *} \\
(16.41)\end{array}$ \\
\hline On-the-run premium & & & $\begin{array}{l}1.00^{* *} \\
(96.90)\end{array}$ & & $\begin{array}{l}0.54^{* *} \\
(34.14)\end{array}$ \\
\hline CG & & & & $\begin{array}{c}0.61^{* *} \\
(51.12)\end{array}$ & $\begin{array}{c}0.14^{* *} \\
(15.70)\end{array}$ \\
\hline Adjusted $R^{2}$ & 0.72 & 0.58 & 0.78 & 0.50 & 0.87 \\
\hline
\end{tabular}

Table 2: Regression Results

The table reports the results of standard regressions with the ten-year at-the-money TIPS deflation option value measured as a par-yield spread as the dependent variable and four measures of financial market uncertainty and functioning as explanatory variables. T-statistics are reported in parentheses. Asterisks ${ }^{*}$ and ${ }^{* *}$ indicate significance at the 5 percent and 1 percent levels, respectively. The data are daily covering the period from January 4, 2005, to March 31, 2017. Note that data between August 9, 2011, and June 19, 2013, are excluded from the sample.

variables are used to control for the TIPS market's limits to arbitrage and other pricing factors that reflect either TIPS market liquidity specifically or bond market liquidity more broadly. The first of those included is inspired by the analysis in $\mathrm{Hu}$ et al. (2013). They demonstrate that deviations in bond prices in the Treasury securities market from a fitted yield curve represent a measure of noise and illiquidity caused by limited availability of arbitrage capital. Their analysis suggests that such measures represent risk factors that carry a premium across many financial markets. Thus, they can be interpreted as representing economy-wide illiquidity measures that should affect all financial markets. Given our focus on the TIPS market, we choose to use the average absolute fitted error reported in the Gürkaynak et al. (2010, henceforth GSW) database, which measures deviations in TIPS prices from a smooth Svensson (1995) yield curve across the maturity spectrum. The second variable is the yield difference between seasoned (off-the-run) Treasury securities and the most recently issued (onthe-run) Treasury security of the same maturity shown in Figure 1. As already noted, the on-the-run security is typically the most traded security and therefore penalized the least in terms of liquidity premiums, which explains the mostly positive spread. For our analysis, the important thing to note is that if there is a wide yield spread between liquid on-the-run and comparable seasoned Treasuries, we would expect any liquidity premiums in the TIPS market to also be elevated. The third and final variable represents a measure of priced frictions in the markets for TIPS and inflation swaps described in Christensen and Gillan (2017, henceforth CG) and measured as the difference between the 10-year inflation swap rate (downloaded 


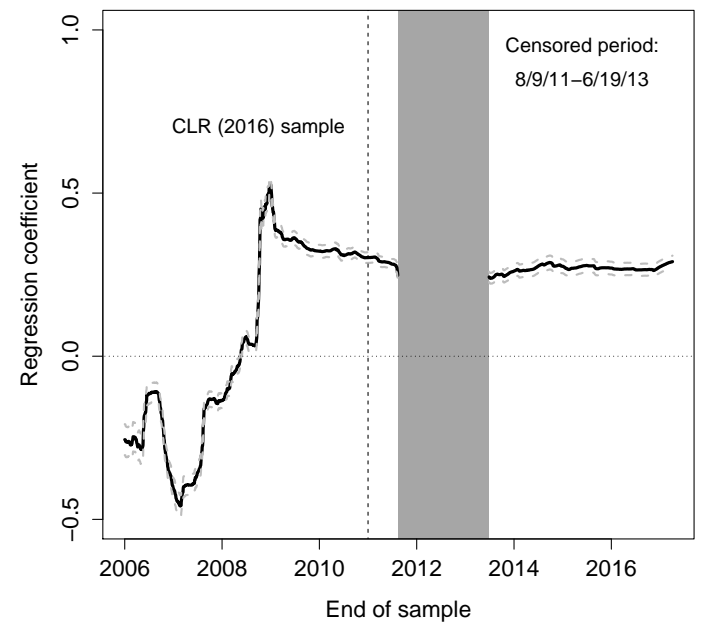

(a) VIX

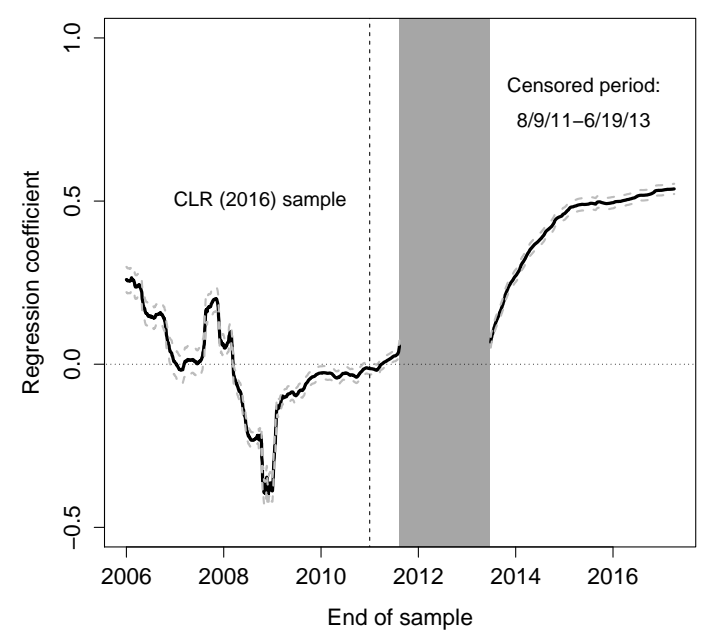

(c) Treasury on-the-run premium

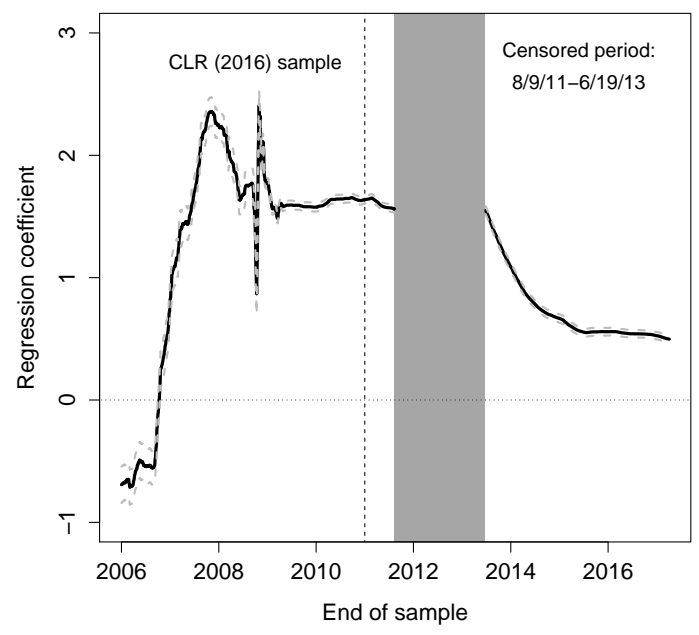

(b) GSW

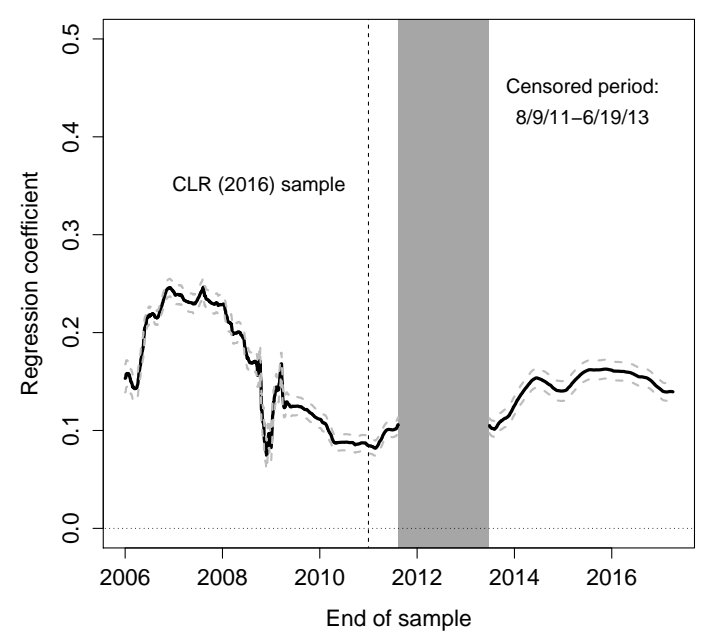

(d) CG

Figure 7: Regression Coefficients from Expanding Samples

Each panel shows the estimated coefficient on the indicated variable using expanding samples in regression (5) in Table 2. Dashed grey lines indicate one standard-deviation confidence bands.

from Bloomberg) and the 10-year TIPS breakeven inflation calculated from the Gürkaynak et al. $(2007,2010)$ yield databases.

Using daily data from January 2005 through March 2017, but censoring the period from August 9, 2011, through June 19, 2013, Table 2 reports the results of the regressions based on the full sample that ends on March $31,2017 .{ }^{9}$ First, all four explanatory variables are im-

\footnotetext{
${ }^{9}$ The data used in the regressions starts in January 2005 for two reasons. First, the inflation swap data used in the construction of the CG measure is not densely populated until late 2004. Second, the CLR model estimation requires a certain minimum sample length of TIPS yields to appropriately capture the joint factor dynamics of nominal and real yields.
} 


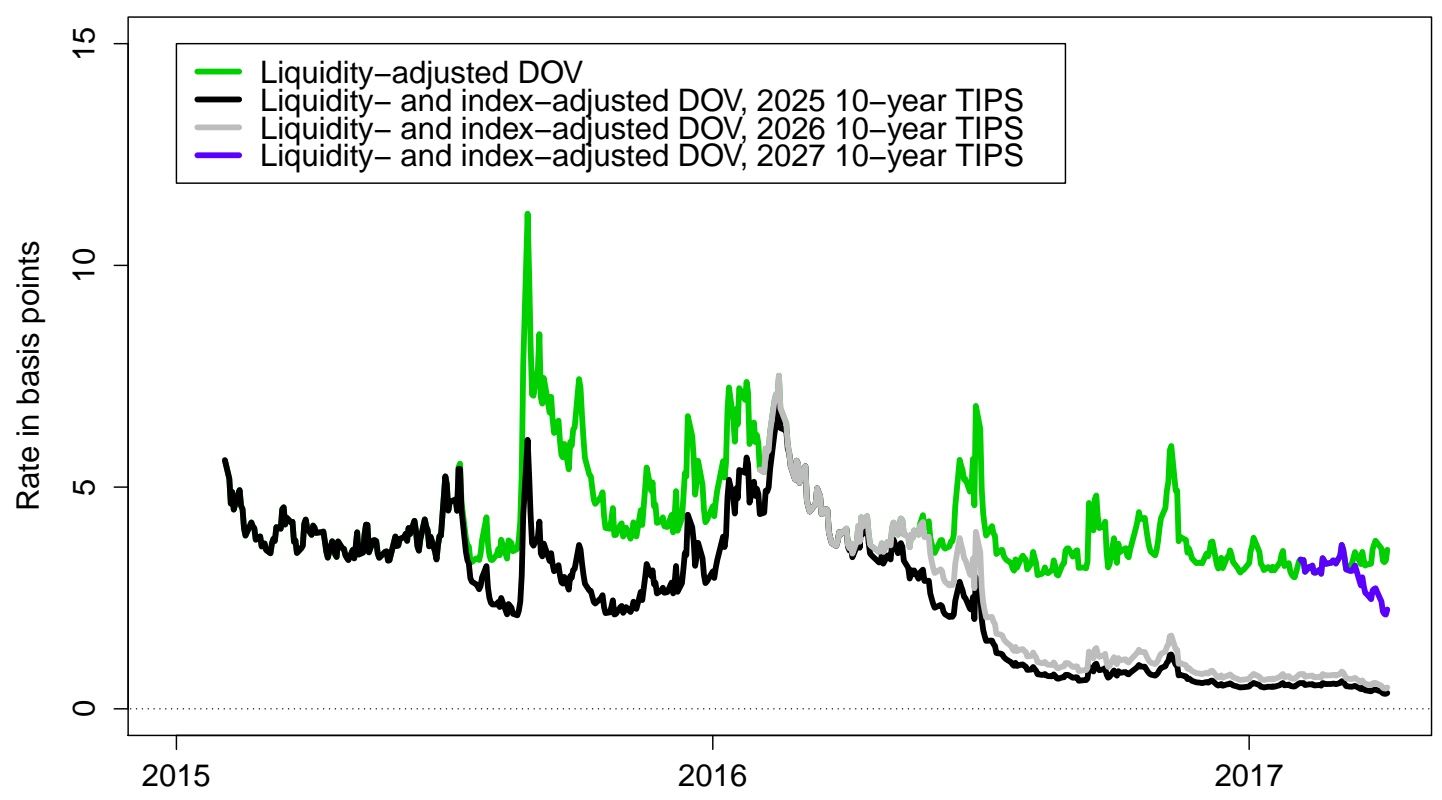

Figure 8: Liquidity- and Index-Adjusted Deflation Option Values

portant and have high statistical significance individually with positive regression coefficients as expected. Second, once combined, these results are preserved for all four variables and the adjusted $R^{2}$ increases to 0.87 .

To asses the stability of the regression coefficients, we run regression (5) in Table 2 on expanding samples starting in January 2006 and up until March 31, 2017, but with the period between August 9, 2011, and June 19, 2013, still censored. The estimated regression coefficients are illustrated in Figure 7 . We note that all regression coefficients are very stable during the period since January 2015 we use in our analysis. Moreover, the censoring seems to have a minimal impact on our results. Most importantly, the coefficient on the VIX is particularly stable, which is what is really required for our approach to be valid.

To get a real-time estimate of the true value of the deflation protection option embedded in the price of the newly issued 10-year TIPS in our TIPS pairs, we use the coefficient on the VIX in regression (5) multiplied by the VIX, i.e. $\widehat{\beta}_{V I X}(t) \times V I X(t)$, where $t$ indicates the end date of the regression sample. Thus, we are relying on the historical relationship between the deflation option value and the VIX, while controlling for liquidity effects, to project liquidity-adjusted values of the deflation option conditional on observed realizations of the VIX. The solid green line in Figure 8 shows the real-time liquidity-adjusted deflation option values constructed in this way. 


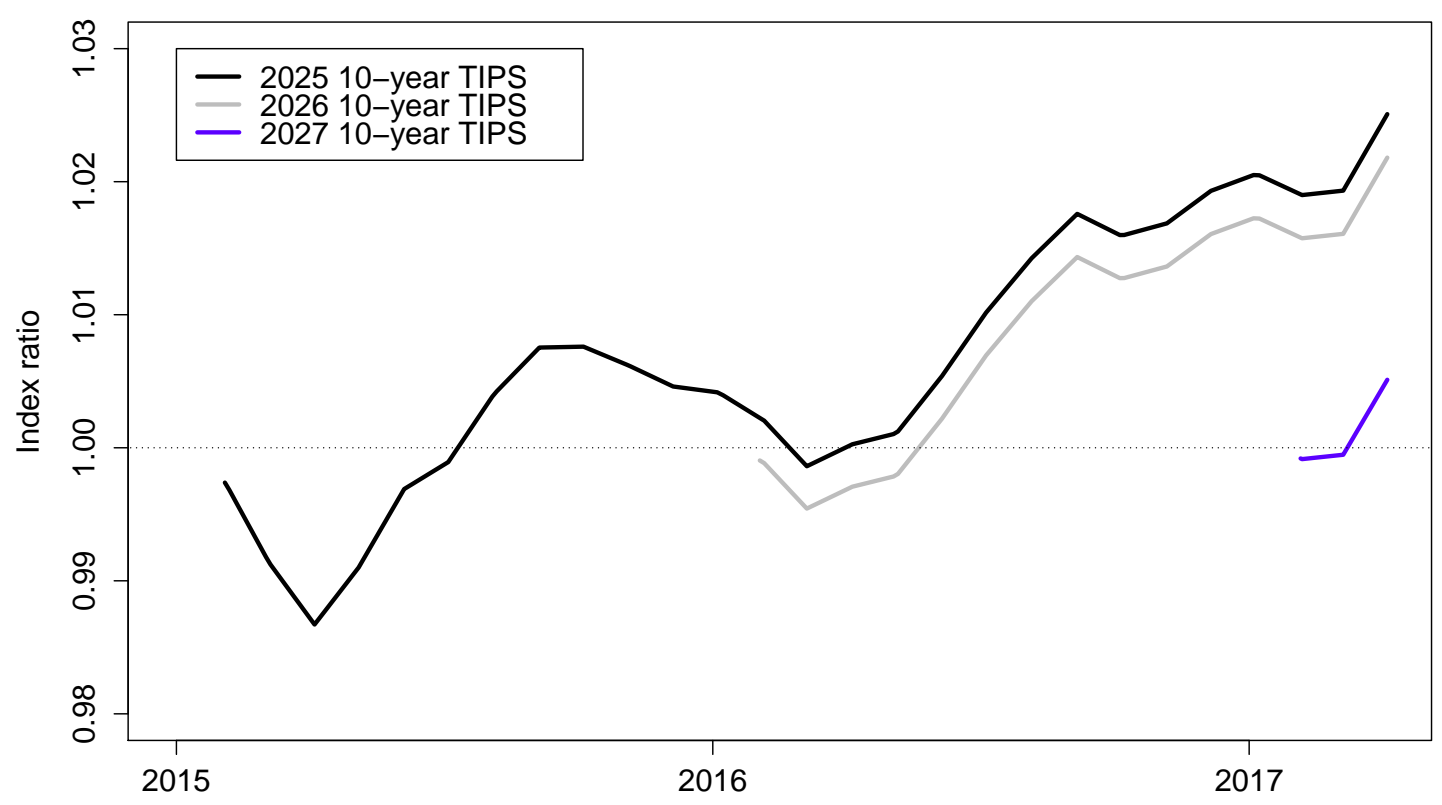

Figure 9: Index Ratios of 10-Year TIPS

\subsection{Liquidity- and Index-Adjusted Deflation Option Values}

In this section, we make a simple refinement to the liquidity-adjusted deflation option values to adjust for their accumulated inflation exposure. To do so, we exploit the security-specific information reflected in the inflation index ratios for the recently issued 10-year TIPS in each of our matching TIPS pairs. Since inflation has been mostly positive since 2015, the deflation protection options embedded in the prices of the new 10-year TIPS in our pairs gradually become more and more out of the money, which should be accounted for.

To begin, let $\widehat{D O V}_{A T M}(t)$ denote the liquidity-adjusted at-the-money deflation option values described so far. We propose to use the security-specific inflation index ratio, $I_{t}$, to make the following simple inflation-index adjustment to $\widehat{D O V}_{A T M}(t)$ :

$$
D O V\left(I_{t}\right)=\widehat{D O V}_{A T M}(t) \cdot \min \left\{1, \exp \left(-\bar{\beta}\left(I_{t}-1\right)\right)\right\}
$$

where $\bar{\beta}$ is a positive parameter that can be freely calibrated, while the minimum operator is imposed to reflect the notion that the option value is unlikely to exceed its original atthe-money value. In light of the generally inflationary environment experienced in the postwar period, we consider this a reasonable assumption about investors' longer-term inflation outlook that is also consistent with readings of long-term inflation expectations from surveys of professional forecasters. For the same reason we consider the brief dips in the inflation 
indexation ratios below 1 observed in Figure 9 to represent temporary seasonal effects that are without importance for the value of long-term deflation options.

In our calibration, we fix $\bar{\beta}$ such that by the time a 10 -year TIPS has accrued $5 \%$ inflation compensation, its deflation option is sufficiently out of the money such as to have lost 99 percent of its original value; i.e., $\bar{\beta}$ must satisfy the equation:

$$
\exp (-\bar{\beta}(1.05-1))=0.01 \Longleftrightarrow \bar{\beta}=-\frac{\log 0.01}{0.05}=92.1034
$$

Using this value for $\bar{\beta}$ in combination with the information about $I_{t}$ for each of the newly issued 10-year TIPS in our TIPS pairs produces the liquidity- and index-adjusted $D O V_{t}$ series shown in Figure 8, which we use in our assessment of an on-the-run premium in the next section.

\section{The Premium on Recently Issued TIPS}

The starting point for our analysis is the observed differences in yields to maturity for the 2025, 2026, and 2027 TIPS pairs shown in Figure 3. They are each positive on average, but only marginally so. However, as discussed in the previous section, two adjustments are needed to account for the estimated values of their embedded deflation options and the differences in coupon rates across securities.

To begin the description of our yield spread decomposition, Figure 10 shows the observed yield spread for the 2025 TIPS pair with a solid black line. The first step is to account for the deflation protection options embedded in the TIPS contract. The value of the deflation option within the seasoned 20-year TIPS is assumed to be zero since cumulative inflation over the past decade has been positive and cannot possibly be erased over the remaining time to maturity. ${ }^{10}$ Thus, we only need to account for the deflation option in the recently issued 10-year TIPS. Based on the regression results described in Section 5.2 and the refinement utilizing the information in the inflation index ratios of the 10-year TIPS described in Section 5.3 , we identify the contribution of the liquidity- and index-adjusted deflation option value in the spread of the 2025 TIPS pair shown with a solid red line in Figure 10. This effect averages 2.6 basis points over the shown period.

Second, the yield to maturity of a bond varies with the level of its coupon rate for a given discount function and for fixed coupon and principal payment dates. Adjusting for the effect of the coupon differential is particularly germane here since the general level of interest rates has declined notably over the past ten years. As a result, the coupon rates on the seasoned 20-year bonds $(2.375 \%, 2 \%$, and $2.375 \%$, respectively) are much higher than the coupon rates on the matching recently issued 10 -year bonds $(0.25 \%, 0.625 \%$, and $0.375 \%$,

\footnotetext{
${ }^{10}$ Since these index ratios are close to 1.2 , it would require 20 percent net deflation just to bring their embedded deflation options near the money, an outcome we consider practically impossible to occur in less than 10 years.
} 


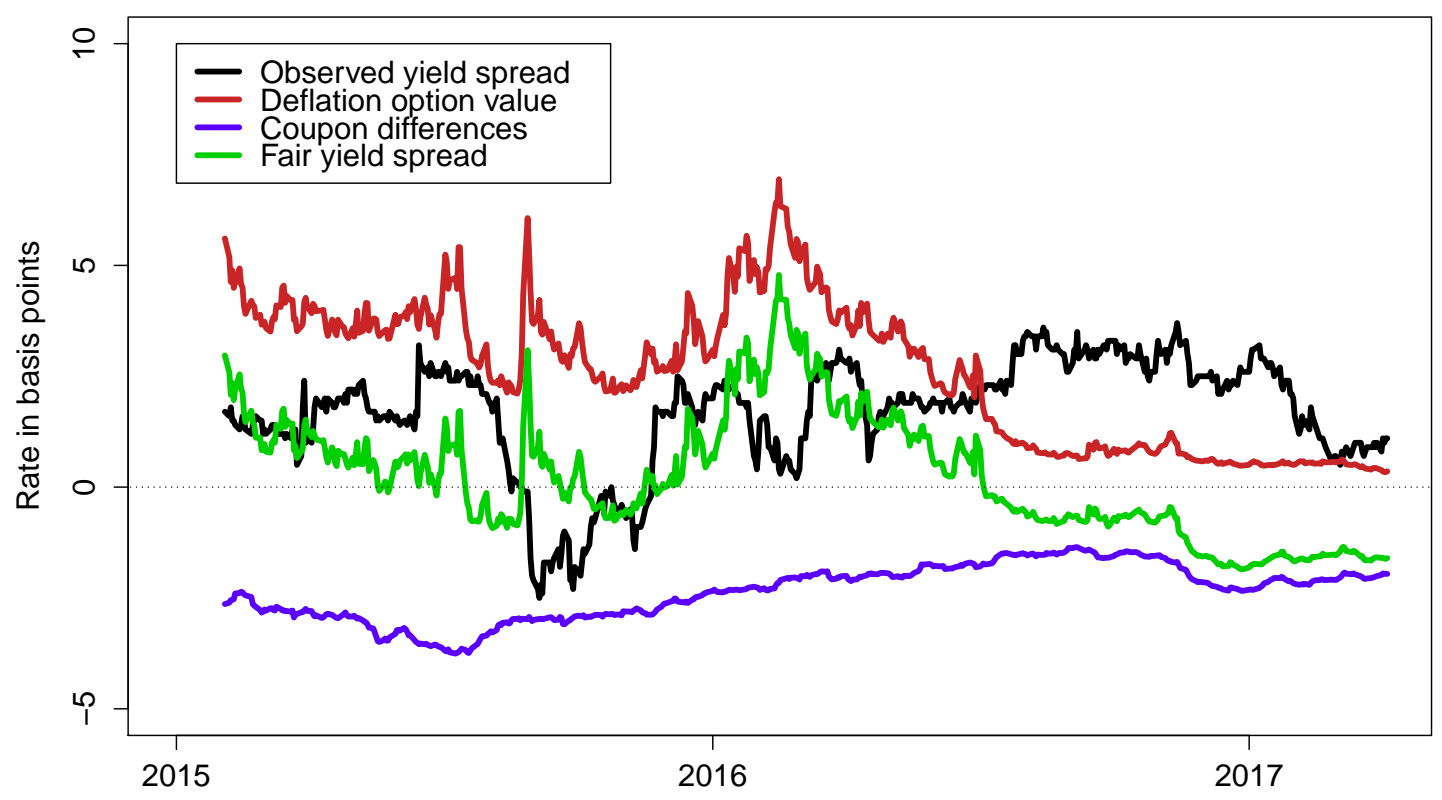

Figure 10: Decomposition of the Yield Spread of the 2025 TIPS Pair

respectively). To account for this effect, we use the CLR model's daily estimated TIPS yield curve to generate the yields to maturity for the individual bonds based on the discounted values of their remaining cash flows, neglecting the value of their deflation protection. The difference between a TIPS pair's yields to maturity calculated this way mainly represents the differences in coupon rates and is shown with a solid blue line in Figure 10 for the 2025 TIPS pair. The differences are on the order of 2 to 3 basis points in favor of the seasoned TIPS, which explains the negative sign.

Now, combining the effect of the liquidity- and index-adjusted deflation option values with the adjustment for the coupon differences, we get the fair yield spread that we would expect to prevail between the seasoned and newly issued TIPS in the 2025 TIPS pair under an assumption of fair pricing. This series is shown with a solid green line in Figure 10 and is barely positive, averaging 0.25 basis point. The differences between the TIPS pairs' observed yield spreads and the estimated fair yield spreads described above for the 2025 TIPS pair represent our estimate of the premium on the recently issued TIPS. Figure 11 shows these series for all three pairs of TIPS.

Overall, these estimated TIPS premiums are fairly small in magnitude. The premium for the 2025 TIPS pair ranges from -4.4 basis points to 4.9 basis points and averages just 1.4 basis point. For the 2026 pair, the range is from 0.2 basis point to 6.7 basis points with an average of 4.2 basis points. Finally, for the 2027 pair, there is only a limited sample 


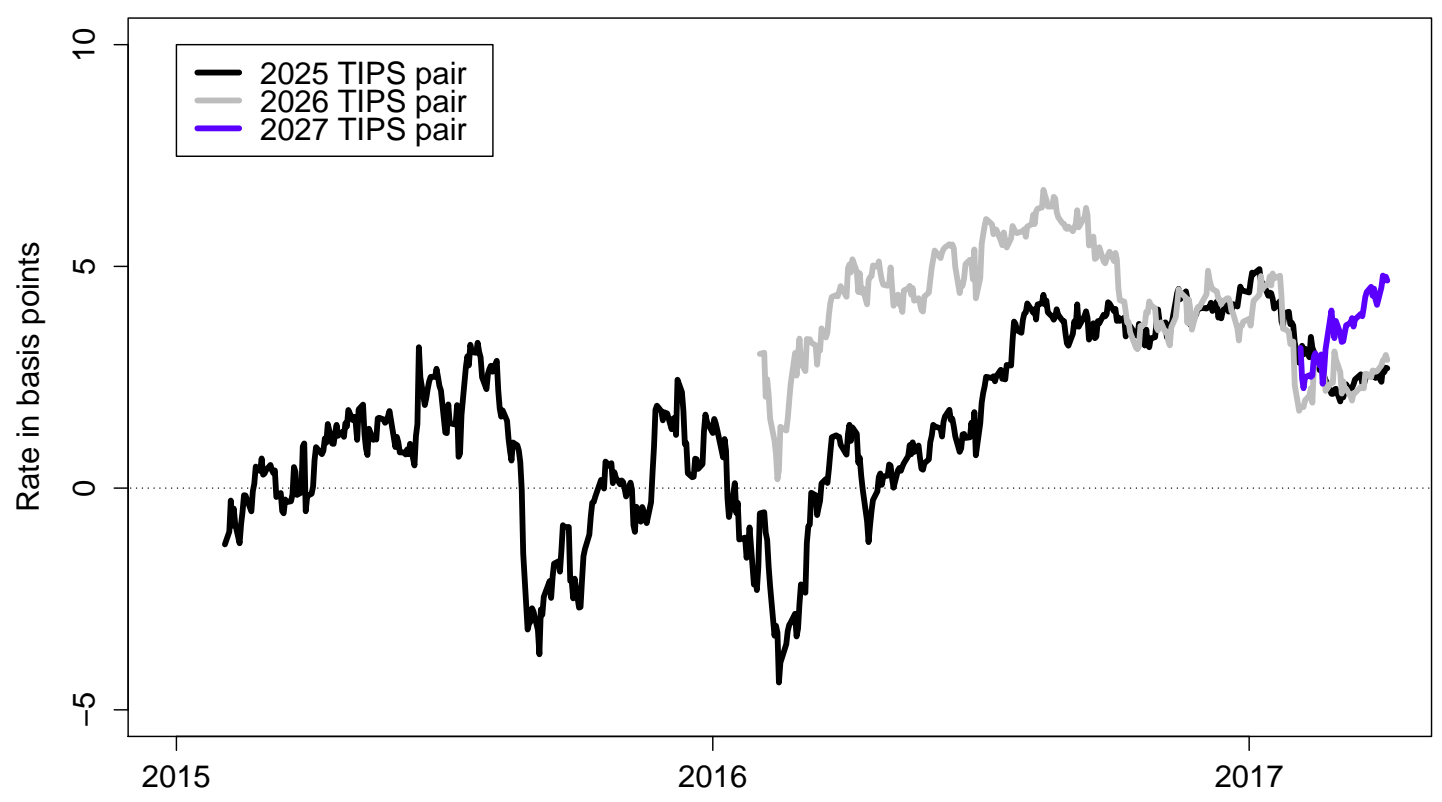

Figure 11: Estimated Net Premium of Recently Issued TIPS

with a range from 2.3 basis points to 4.8 basis points with an average of 3.6 basis points. Thus, our results suggest that there is a small positive premium on newly issued 10-year TIPS, and it is persistent in that it continues to exist long after new 10-year TIPS are issued. This observation leads us to conclude that these premiums are different from the on-the-run premiums found in the Treasury market and described in Section 2.

We note that the premium tends to dip when financial market uncertainty is elevated as happened in August 2015 and January 2016. This pattern is caused by the fact that during such episodes the deflation option value goes up, which raises the fair yield spread. At the same time, the observed yield spreads are either stable or decline. This result suggests that the deflation option is not a major driver of the variation in the observed yield spreads for our TIPS pairs. As a consequence, it is likely other fundamental factors determine the size of the premiums on recently issued TIPS.

Although our results could be interpreted as suggesting that premiums on recently issued TIPS are potentially negligible, we stress that several caveats exist regarding such a conclusion. As can be gleaned from Figure 1, on-the-run premiums in the standard Treasury market have been below average during the period under analysis; accordingly, our results could simply be a reflection of that phenomenon. Going forward, though, it will be straightforward to monitor these spreads and the new TIPS pairs that will come into existence. Another helpful development should be that the economy will continue to experience positive inflation 
in the years ahead that will quickly reduce the deflation option values to zero, leaving only the coupon adjustment to consider. While the current evidence suggests that the TIPS market has a small on-the-run premium, more evidence will be provided over the next few years to answer this question more completely.

We stress that our finding of a small on-the-run premium in 10-year TIPS is consistent with the results reported by Fleming and Krishnan (2012). They find that on-the-run TIPS do tend to be more liquid as reflected in lower bid-ask spreads, greater trading volumes, and

larger trade sizes in addition to higher trading frequencies. At the same time, and maybe somewhat surprisingly, they fail to detect any material price differences relative to comparable seasoned TIPS. Furthermore, the persistent effects we document share similarities with the results reported by Fleming (2002). He finds that re-opened 52-week Treasury bills that are larger than comparable 26-week Treasury bills in terms of outstanding notional amounts have yields that average 2.4 basis points higher despite having lower bid-ask spreads and higher trading volumes. This relative price pattern continues to exist after both bills have been re-opened as 13-week Treasury bills and no longer are on the run. In short, intriguing and persistent price differences not limited to the on-the-run period appear to exist in both Treasury and TIPS markets.

\section{Conclusion}

In this paper, we conduct a careful analysis of the yield spreads between pairs of TIPS that are identical except for the fact that one is recently issued, while the other has been outstanding for more than ten years. Adjusting for differences in the value of the deflation protection offered by each TIPS and their coupon rates, we find a residual unexplained premium on recently issued TIPS that is small, positive, and persists long after new 10-year TIPS have been issued. This finding suggests that the premiums we report are different from the wellknown on-the-run premiums in the Treasury market that has attracted much attention in the literature.

However, we caution that, as more matching pairs of TIPS come on line in coming years, this type of analysis could potentially change the interpretation of our results. We therefore encourage others to pursue this type of research in the future. Finally, we note that our findings could matter for models of the relative pricing patterns among TIPS such as the liquidity-augmented dynamic term structure model studied in Andreasen et al. (2017). Also, our results could have implications for the pricing of derivatives tied to the TIPS market such as inflation swaps, caps, and floors. However, we also leave these issues for future research. 


\section{Appendix: Analysis of Individual TIPS Prices}

One concern about the analysis in the main text is that it is not clear whether the documented premiums of recently issued TIPS over matching seasoned TIPS are due to a premium on new securities or a penalty on seasoned securities. Therefore, in this appendix, we pursue a different strategy as a robustness check in which we assess the specialness of each TIPS relative to a fitted TIPS yield curve. For this purpose we use both the estimated TIPS yield curves implied by the CLR model as in the main text and the TIPS yield curves constructed by Gürkaynak et al. (2010), henceforth referred to as GSW (2010). The latter serves as the benchmark in this exercise since it represents a model-free alternative that we can use to analyze the individual yields in our TIPS pairs.

The way we proceed is to discount the cash flow of each TIPS in our TIPS pairs using the fitted TIPS yield curves and convert the resulting bond price into the equivalent yield to maturity. By deducting this fitted synthetic yield from the corresponding observed yield from Bloomberg, we get a measure of how far away the price of each TIPS is from the fitted TIPS yield curve that is supposed to smooth through idiosyncratic pricing errors. For this reason we refer to this deviation as the specialness of each TIPS.

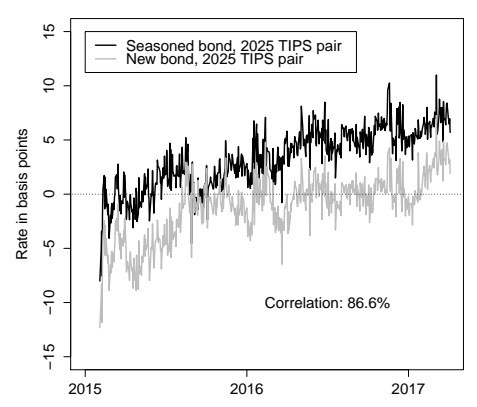

(a) 2025 TIPS pair

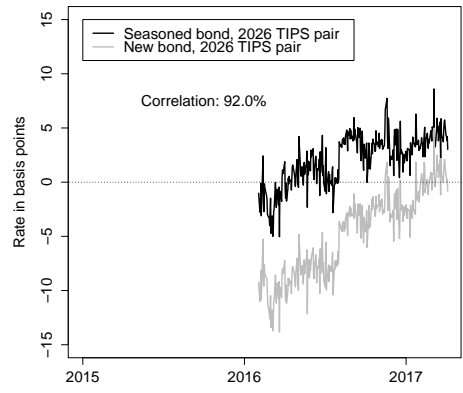

(b) 2026 TIPS pair

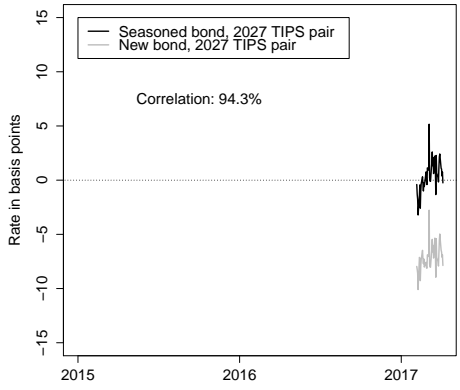

(c) 2027 TIPS pair

Figure 12: Specialness of Individual TIPS

Figure 12 shows these measures of specialness for the individual securities in our three TIPS pairs constructed using the daily GSW (2010) TIPS yield curves. First, these measures are very highly correlated for the TIPS in each pair. This suggests that the deviations from the fitted GSW (2010) TIPS yield curves are not security-specific. Rather, they appear to reflect systematic mismeasurement by the constructed GSW (2010) TIPS yield curves for TIPS yields in the 8- to 9-year maturity range. Furthermore, this pattern is pervasive and clearly not unique to recently issued TIPS as there are no distinct changes around the time new 10-year TIPS are issued.

Now, by taking the difference between the specialness premiums of each TIPS in our TIPS pairs, we obtain the coupon-adjusted yield spreads for our three TIPS pairs as already discussed in the main text. This can be done both based on the estimated TIPS yield curves from the CLR model and by using the TIPS yield curves constructed by GSW (2010).

The resulting yield spreads from both approaches for all three TIPS pairs are shown in Figure 13. First, note that both approaches deliver very similar results, which is not surprising since the CLR model is estimated using the GSW (2010) TIPS yields and in general achieves a very good fit to that data. Still, we take this to imply that the estimated coupon-adjusted yield spreads for our three TIPS pairs are robust and not very model sensitive.

Second, the coupon-adjusted yield spreads are uniformly positive. However, as already explained earlier, their level is a function of the value of the deflation protection option in the recently issued TIPS, which needs to be accounted for as before. 


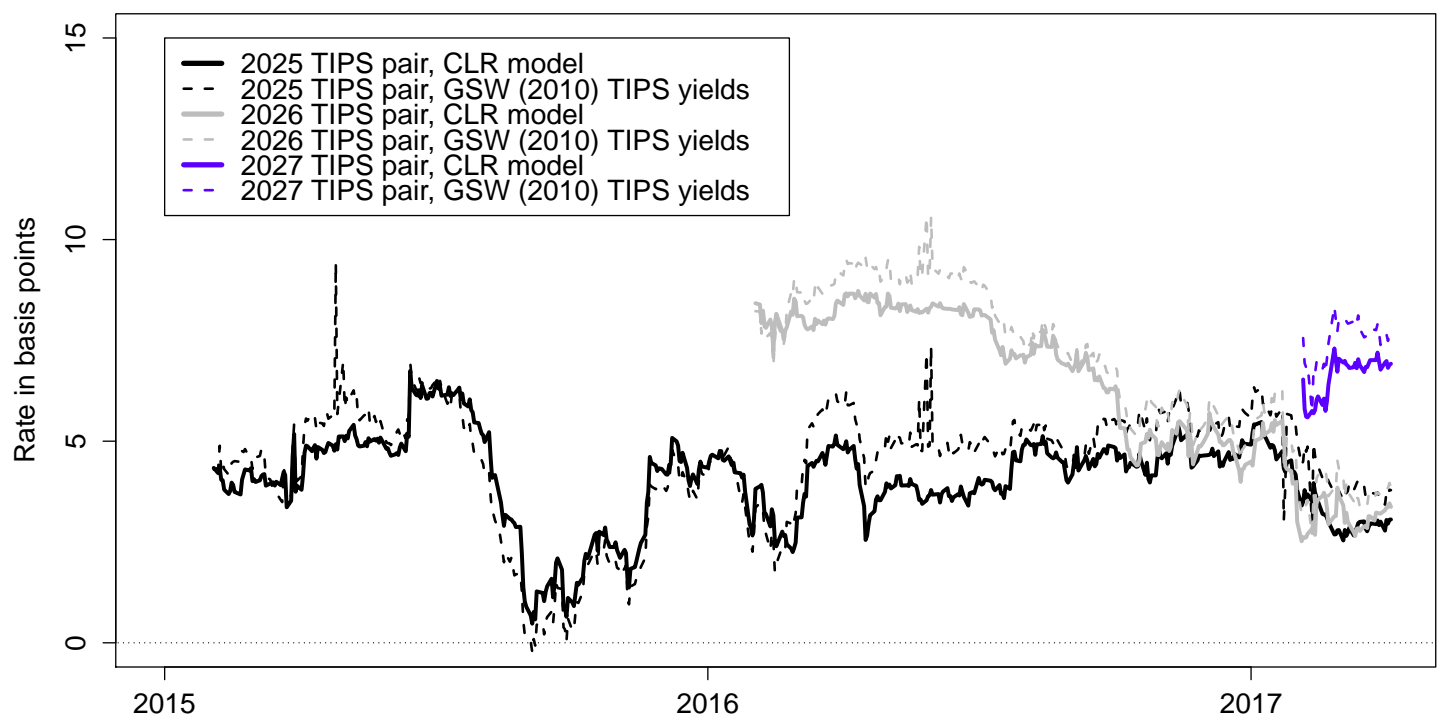

Figure 13: Coupon-Adjusted Yield Spreads of TIPS Pairs

To adjust the spreads for the value of the embedded deflation protection option, would take us back to the analysis in Section 5 and be the same for both approaches. Therefore, in light of the closeness of the coupon-adjusted yield spreads shown in Figure 13, we would arrive at essentially the same net premium of recently issued TIPS as already reported whether we use the GSW (2010) TIPS yields considered here or the CLR model-implied TIPS yields used in the existing analysis. 


\section{References}

Amihud, Yakov and Haim Mendelson, 1991, "Liquidity, Maturity, and the Yields on U.S. Treasury Securities," Journal of Finance, Vol. 46, No. 4, 1411-1425.

Andreasen, Martin M., Jens H. E. Christensen, and Simon Riddell, 2017, "The TIPS Liquidity Premium," Working Paper 2017-11, Federal Reserve Bank of San Francisco.

Barclay, Michael J., Hendershott, Terrence, and Kotz, K., 2006, "Automation versus Intermediation: Evidence from Treasuries Going Off-the-Run," Journal of Finance, Vol. 61, 2395-2414.

Cheridito, Patrick, Damir Filipović, and Robert L. Kimmel, 2007, "Market Price of Risk Specifications for Affine Models: Theory and Evidence," Journal of Financial Economics, Vol. 83, No. 1, 123-170.

Christensen, Jens H. E. and James M. Gillan, 2017, "Does Quantitative Easing Affect Market Liquidity?," Working Paper 2013-26, Federal Reserve Bank of San Francisco.

Christensen, Jens H. E., Jose A. Lopez, and Glenn D. Rudebusch, 2010, "Inflation Expectations and Risk Premiums in an Arbitrage-Free Model of Nominal and Real Bond Yields," Journal of Money, Credit and Banking, Supplement to Vol. 42, No. 6, 143-178.

Christensen, Jens H. E., Jose A. Lopez, and Glenn D. Rudebusch, 2016, "Pricing Deflation Risk with U.S. Treasury Yields," Review of Finance, Vol. 20, No. 3, 1107-1152.

Dai, Qiang and Kenneth J. Singleton, 2000, "Specification Analysis of Affine Term Structure Models," Journal of Finance, Vol. 55, No. 5, 1943-1978.

Duffie, Darrell, 1996, "Special Repo Rates," Journal of Finance, Vol. 51, No. 2, 493-526.

Fleckenstein, Mathias, Francis A. Longstaff, and Hanno Lustig, 2014, "The TIPS-Treasury Bond Puzzle," Journal of Finance, Vol. 69, No. 5, 2151-2197.

Fleming, Michael J., 2002, "Are Larger Treasury Issues More Liquid? Evidence from Bill Reopenings," Journal of Money, Credit and Banking, Vol. 34, No. 3, 707-735.

Fleming, Michael J. and Neel Krishnan, 2012, "The Microstructure of the TIPS Market," Federal Reserve Bank of New York Economic Policy Review, Vol. 18, No. 1, 27-45.

Fontaine, Jean-Sébastien and René Garcia, 2012, "Bond Liquidity Premia," Review of Financial Studies, Vol. 25, No. 4, 1207-1254.

Goldreich, David, Bernd Hanke, and Purnendu Nath, 2005, "The Price of Future Liquidity: Time-Varying Liquidity in the U.S. Treasury Market," Review of Finance, Vol. 9, 1-32. 
Graveline, Jeremy J. and McBrady, Matthew R., 2011, "Who Makes On-the-Run Treasuries Special?," Journal of Financial Intermediation, Vol. 20, 620-632.

Gürkaynak, Refet S., Brian Sack, and Jonathan H. Wright, 2007, "The U.S. Treasury Yield Curve: 1961 to the Present," Journal of Monetary Economics, Vol. 54, No. 8, 22912304 .

Gürkaynak, Refet S., Brian Sack, and Jonathan H. Wright, 2010, "The TIPS Yield Curve and Inflation Compensation," American Economic Journal: Macroeconomics, Vol. 2, No. 1, 70-92.

Hu, Grace Xing, Jun Pan, and Jiang Wang, 2013, "Noise as Information for Illiquidity," Journal of Finance, Vol. 68, No. 6, 2341-2382.

Keane, Frank, 1996, "Repo Rate Patterns for New Treasury Notes," Current Issues in Economics and Finance, Vol. 2, No. 10, 1-6.

Krishnamurthy, Arvind, 2002, "The Bond/Old-Bond Spread," Journal of Financial Economics, Vol. 66, 463-506.

Nelson, Charles R. and Andrew F. Siegel, 1987, "Parsimonious Modeling of Yield Curves," Journal of Business, Vol. 60, No. 4, 473-489.

Sarig, Oded and Arthur Warga, 1989, "Bond Price Data and Bond Market Liquidity," Journal of Financial and Quantitative Analysis, Vol. 24, No. 3, 367-378.

Svensson, Lars E. O., 1995, "Estimating Forward Interest Rates with the Extended Nelson \& Siegel Method," Quarterly Review, Vol. 3, Sveriges Riksbank, 13-26.

Swanson, Eric T. and John C. Williams, 2014, "Measuring the Effect of the Zero Lower Bound on Medium- and Longer-Term Interest Rates," American Economic Review, Vol. 104, No. 10, 3154-3185.

Warga, Arthur, 1992, "Bond Returns, Liquidity, and Missing Data," Journal of Financial and Quantitative Analysis, Vol. 27, No. 4, 605-617. 